\title{
COVID-19: Twin Research in Progress/Twin Research Reviews: Asthmatic and Nonasthmatic Twins; Stanford University Study of Anal Prints; Twin Mammals and COVID-19; Twin Delivery and the Three 'Rs'/Mixed Media: The Rainman Twins - The Film; Twins Irish Pub; Twins 'Covid and Corona'; Death of a Surgeon Who Separated Conjoined Twins; Twinco — Twin-Based Supply Company
}

\author{
Nancy L. Segal \\ Department of Psychology, California State University, Fullerton, CA, USA
}

\begin{abstract}
It is likely that genetic factors play a role in the susceptibility to, and recovery from, COVID-19. A survey of ongoing twin research could produce findings likely to help in the prevention and management of this pandemic. This survey is followed by a review of research comparing selected features of asthmatic and nonasthmatic twins, links between twin mammals and COVID-19, and relationships between twin delivery and the three 'Rs'. The final section of this article presents newsworthy twin-related items, some associated with COVID-19. They include a summary of the Rainman Twins film, a study of anal prints, the 'Twins' Irish pub, newborn twins 'Covid and Corona', the death of a surgeon who separated conjoined twins, and Twinco, a twin-based supply company.
\end{abstract}

\section{COVID-19: Twin Research in Progress}

Genetic factors play a significant role in the onset and course of many diseases and medical conditions. Therefore, it is likely that genetically based individual differences will underlie susceptibility to, and recovery from, COVID-19 infection. A number of ongoing twin research investigations could produce findings likely to help in the prevention and management of this virus. I will begin by describing several cases that illustrate how a person's particular genetic profile may affect their response to exposure and infection from COVID-19, and the H1N1 virus that caused the 1918 pandemic. Two of the three cases involve twins, one does not.

British twin sisters, Katy and Emma Davis, were both health care workers - Katy was a nurse and Emma was a former nurse (BBC News, 2020). The twins appeared to be identical, based on photographs. Sadly, Katy and Emma passed away within days of one another at the age of 37 years, following COVID-19 infection. The twins also suffered from other health conditions that were only described as being the same, so perhaps both were especially susceptible to COVID-19; both twins were known to have been unwell

Author for correspondence: Nancy Segal, Email: nsegal@fullerton.edu

Cite this article: Segal NL. (2020) COVID-19: Twin Research in Progress/Twin Research Reviews: Asthmatic and Nonasthmatic Twins; Stanford University Study of Anal Prints; Twin Mammals and COVID-19; Twin Delivery and the Three 'Rs'/Mixed Media: The Rainman Twins - The Film; Twins Irish Pub; Twins 'Covid and Corona'; Death of a Surgeon Who Separated Conjoined Twins; Twinco - Twin-Based Supply Company. Twin Research and Human Genetics 23: 259-263, https://doi.org/10.1017/ thg.2020.59 for some time. It seems likely that Katy contracted the infection first since she was still working as a hospital nurse, and later passed it on to her sister with whom she was living.

In April 2020, male twin Philip Kahn passed away from COVID-19 infection at the age of 100 years. Kahn was living in New York City and was healthy up until that point, but his age most likely increased his susceptibility to the virus. His story is unique because his twin brother Samuel passed away as a young infant from H1N1 infection during the pandemic of 1918 (Seelye, 2020). It is unknown whether these twins were monozygotic (MZ) or dizygotic (DZ), but if they were DZ it could be that Philip had a more robust immune system than his twin brother. Consistent with this possibility is a pair of nontwin sisters, Selma and Esther Ryan. Selma passed away recently from COVID-19 at the age of 96 years, whereas Esther died from the Spanish flu 102 years ago. The sisters never knew one another, just like the Kahn twins. Philip Kahn served in World War II and later worked as an electrical foreman. He helped to build the World Trade Center and the first New York City blood bank. He was a physically active individual who enjoying swimming, social dancing and dancing on roller skates. The death of his twin was a loss that he felt quite strongly throughout his lifetime.

Sylvia Goldsholl is not a twin, but her story exemplifies inherited individual differences in response to infection (Kilgannon, 2020). Goldsholl, who lives in an Allendale, New Jersey senior living community, contracted COVID-19 at the age of 108 years. She was apparently healthy throughout her life, having survived the 1918 pandemic, two world wars and the Great Depression. 
However, despite her age that made her survival unlikely, she was able to fully recover.

The following twin-based research projects on COVID-19 are now in progress. Their results promise to enhance understanding of the different susceptibilities and outcomes described in the three cases outlined above, and in the general population. The investigators of these projects submitted this information to ISTS President Jeffrey Craig, in response to his April 2020 letter asking who among the membership was engaging in or planning such efforts. All individuals who responded agreed to a brief review of their studies in TRHG.

John Hopper, Australia. Twins Research Australia (TRA) is conducting a study of 'Knowledge, Experience, Reaction and Resilience' (TRACKERR) in the face of the COVID-19 pandemic. The study includes adult twins and the parents of twins. The aim is to quickly determine and report on relevant events within the Australian population. Please see https://www.theage.com.au/ national/thousands-of-australian-twins-join-world-first-studyof-pandemic-impact-20200411-p54j1y.html. Contact: jhopper@ unimelb.edu.au.

Glen Duncan, USA. A COVID-19-related survey has been developed and was administered to the Washington State Twin Registry participants. Baseline data collection has been completed and will be followed up in the future. Plans for a mobility journal and some tracking are in place. Contact: glen.duncan@wsu.edu.

Jaakko Kaprio, Finland. Finland had few infected twins, but there will be a linking of the infectious disease registry (all cases recorded there) with other information, such as income, social benefits, sickness absence and educational attainment. The database also has information on family relationship and household characteristics.

In a joint project between the Danish Twin Registry (Jacob Hjelmborg et al.) and the Finnish Twin Cohort (Miina Ollikainen et al.), Finland will be examining genetic and environmental determinants of methylation patterns of key genes involved in the host response to COVID-19 infection. Contact: jaakko. kaprio@helsinki.fi.

Kaare Christensen, Denmark. Christensen is planning to obtain data by linking the twin registry to the national registers (on symptoms, infected, antibodies, hospitals) that currently are being established. Furthermore, he and his colleagues plan to contact all twins in Denmark in the fall when they expect that their second wave will have passed. Contact: KChristensen@health.sdu.dk.

Antonia Stazi, Italy. An online survey for all twin pairs concerning symptoms and screening, with a focus on stress, was launched in February 2020. A related study is part of a larger project with other populations and will follow twins for 6 months with immunological phenotyping at the baseline, and with monthly screening for COVID-19 positivity. Contact: Antonia.stazi@iss.it.

Tim Spector and colleagues, UK. An app was developed to monitor symptoms in MZ and DZ twins in the UK (https://theconversation. com/our-free-coronavirus-symptom-tracking-app-has-been-used-bytwo-million-people-heres-what-were-learning-134923). The app has now produced data for 3.7 million people worldwide, including a subset of 5000 twins. Contact tim.spector@kcl.ac.uk.

According to Dr Louise Newsom, a general practitioner and menopause specialist in the UK, MZ female twins discordant for hormone replacement therapy (HRT) will be an especially valuable sample (personal communication, May 19, 2020). That is because the more favorable response to COVID-19 by females than males suggests that estrogen may have a protective effect. As an external research colleague on the project, Newsom will be interested in knowing whether an MZ female twin receiving HRT shows fewer or less severe symptoms than her co-twin. Contact: louise. newson@newsonhealth.co.uk.

Dorret Boomsma, the Netherlands. The Netherlands Twin Registry intends to send a dedicated survey to twins and their family members. Contact: di.boomsma@vu.nl.

On behalf of the twin research community, I wish to applaud the efforts of these investigators and the twins and families who are, or will be, participating. If any researcher or research team has a planned or ongoing project concerning twins and the virus, please let me know and I will cover it in an upcoming issue.

\section{Twin Research Reviews}

\section{Asthmatic and Nonasthmatic Twins}

Researchers in California, Pennsylvania and New Jersey have identified asthma as being among the most prevalent of chronic inflammatory lung diseases (Dhondalay et al., 2019). The condition affects an estimated 358,000,000 people worldwide. However, the genetic and phenotypic heterogeneity of the condition challenges medical understanding of its onset and progression. In an attempt to address this concern, Dhondalay et al. (2019) conducted a twin study to examine transcriptomic and methylomic data in asthmatic and nonasthmatic participants. The study sample included 16 female identical twin pairs recruited from the Washington State Twin Registry. Five pairs were concordant for asthma, three pairs were discordant for asthma and eight pairs were concordant for being asthma-free. Peripheral blood mononuclear cells samples were collected from all twins.

Analysis of twins' transcriptomic profiles (sets of RNA transcripts that allow identification of differential gene expression; nature.com, 2020) showed that 9 of the 16 pairs clustered together, while only 2 of 8 twin pairs showed clustering in methylomic profiles (functional assessment of phenotypic expression; Science + Insight, 2020). Two of the three discordant pairs showed clustering in their transcriptomic profiles, a result attributed to 'similarity based on twinness' (p. 990). It was concluded that this exploratory study identified features separating asthmatic and nonasthmatic individuals. The researchers called for future studies that would include a larger number of asthma-discordant twin pairs, as well as male pairs.

The 16 twin pairs in the study were recruited from the Washington State Twin Registry, which assesses twin type by means of a self-report questionnaire (https://wstwinregistry.org/ zygosity-determination-done-by-the-twin-registry/). The twintyping methods used in the asthma study were not described in the report, but I learned that DNA analyses were performed. Twins were classified as DZ if similarities in DNA markers were below 99.0\% (K.C. Nadeau, 2020, personal communication). Other methodological information about the study is available in supplementary material.

\section{Stanford University Study of Anal Prints}

Dr Sanjiv Gambhir and colleagues at Stanford University have devised a toilet that can identify various disease markers in urine and stool that may indicate medical conditions such as colorectal or urological cancers (Armitage, 2020). It is noted that this device could be especially helpful to individuals with genetic predispositions toward irritable bowel syndrome, kidney failure and prostate 
cancer. Other features of the toilet include urinalysis strips to assess certain molecular features - for example, white blood cell count, blood contamination and protein levels that may be linked to some conditions. The device also has a built-in recognition system to ensure the identity of the person using the toilet. This system is based on the biological uniqueness of each person's anal print, analogous to dermatoglyphic characteristics or fingerprints that differ even in MZ twins (Segal \& Montoya, 2018). It was necessary to have this feature in the event that a person using the toilet is not the person who flushes.

Features of the toilet are still being tested. An informative and fascinating addition to this project would involve pairs of MZ and DZ twins. This would allow searching for markers of genetically influenced diseases and determining whether the device could distinguish the anal prints of $\mathrm{MZ}$ co-twins. I proposed this idea to Dr Gambhir, but did not hear back from him. In the midst of the COVID-19 pandemic, his smart toilet could be useful in identifying susceptible and affected individuals. Additional details about this work are available in Park et al. (2020).

\section{Twin Mammals and COVID-19}

The origins of COVID-19 are important to determine. In an unpublished paper, Naser A. Anjum from the Department of Botany at Aligarh Muslim University, in Aligarh, India, described a potential link between 'twin mammals' - bats and pangolins and the deadly virus (Anjum, 2020). Pangolins are the only mammal fully covered in scales (World Wildlife Fund, 2020). In February 2020, pangolins were linked to COVID-19 after Chinese scientists reported that the virus's genetic sequences are 99\% similar in humans and pangolins. However, the findings remain inconclusive (Marshall, 2020).

Anjum (2020) cited work showing that bats are considered to be transmitters of the virus, whereas pangolins may be intermediate hosts. This relationship may explain his use of the term 'twin mammals' since there is nothing notably twin-like between them. The theory behind their relationship is that bats leave a trace of COVID-19 in their droppings, which eventually reach the forest floor. It is there that pangolins could acquire the infection from the excrement. It may be that, eventually, pangolins and/or bats are captured and eaten by humans, causing the disease to spread. Further research is required.

\section{Twin Delivery and the Three 'Rs'}

Research by González-Valenzuela et al. (2020) shows a link between twins' delivery type (vaginal birth vs. cesarean section [C-section]) and cognitive performance. Specifically, C-section delivery was identified as an independent risk factor for various learning disabilities. The twin participants had been born at the Hospital Materno-Infantil, in Málaga, Spain in 2002, and were over 6 years of age and in primary school at the time of the study. Among the 7120 deliveries in 2002, 135 were twin pairs. After omitting some twins due to extreme prematurity, failure to find them and other issues, the final sample included 124 children from 62 twin births. The Kaufman Brief Intelligence Test was used to assess general ability, while selected subtests from the psychopedagogical battery Evalúa-1 were used to assess the ' 3 Rs' reading, writing and 'rithmatic.

In summary, the risk of having a learning disability in reading, writing and arithmetic was three times higher among twins delivered by C-section compared with twins delivered vaginally. None of the dichotomized control variables, such as maternal age at delivery (above or below the age of 35 years) and Apgar score (above or below 7), modified these effects. It would be of interest to know if and how the findings might have changed as a function of zygosity. It is also important to note that it is probably not delivery mode per se that could be causally connected with twins' poorer intellectual outcome - rather, it may be that C-section deliveries occur more often when various prenatal and/or perinatal problems occur.

\section{Mixed Media}

\section{The Rainman Twins - The Film}

Flo and Kay Lyman are the world's only identical female twin autistic savants. The twins, born in 1956, were 52 years of age at the time of filming. Their life histories and extraordinary abilities are the subjects of a 2008, 49-min documentary film titled, The Rainman Twins (Top Documentary Films, 2020). If given a date, the twins are able to identify the day of the week, the weather and what they ate for breakfast. If you name a song, they can recall the artist and release date. The Lyman twins were especially taken with entertainment personality Dick Clark, whose television program American Bandstand was their favorite. The twins were thrilled to meet Clark on several occasions.

The twins came to public attention through television anchor David Wagner, who was fascinated by them. Wagner is now with KIRO-7 TV in Seattle, Washington (KIRO-7, 2020). The twins have been studied at the University of Wisconsin and at the New Jersey Neuroscience Institute; however, their brain structures do not appear to be remarkable, despite their remarkable abilities. I watched this film in the midst of the COVID-19 crisis and highly recommend it.

\section{'Twins' Irish Pub}

Twins is a popular establishment, located at 421 9th Avenue in New York City's Chelsea neighborhood. It first opened in 1970, making it 50 years old this year (Twins Irish Pub, 2020). It was started by Patrick Lunney and named after his twin sons, Patrick and Danny (Legacy, 2020). Lunney, who passed away in 2019, came from Swanlinbar County Cavan, Ireland. He was a member of the O'Luinigh family, whose work in trade hospitality dates back to 1909. Lunney came to the USA in 1960 when he was 27 years old and worked as a bartender in Brooklyn and other New York City locations. His first bar was Lunney's in Orangeburg, New York, followed by Twins. Twins is temporarily closed, but whether that is due to the COVID-19 virus or to Lunney's passing is unknown. A picture of the establishment appears in Figure 1.

\section{Twins COVID and Corona}

Male-female twins, COVID and Corona, were born to an Indian couple, Vinay and Preeti Verma, after the COVID-19 virus spread across the globe (Kaiser, 2020). The babies, who weighed $2.9 \mathrm{~kg}$ and $2.7 \mathrm{~kg}$, respectively, were delivered by C-section following complications. Many people may be surprised and shocked by the parents' choice of names, given their association with something so unpleasant. The twins' mother explained that she is aware of the apprehension surrounding COVID-19 and wanted to ease the anxiety and fear caused by that word. Time will tell if she chose wisely. 


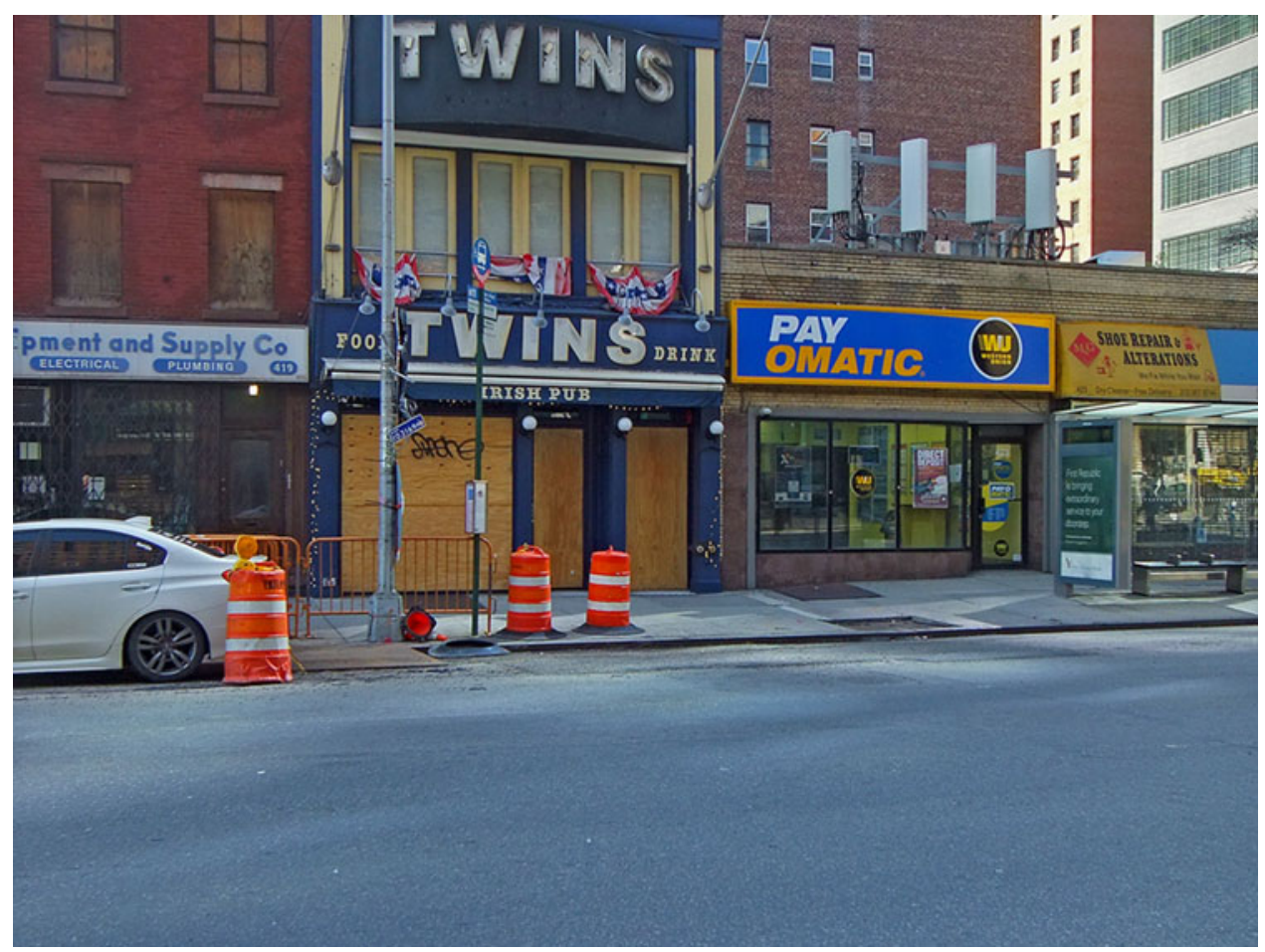

Fig. 1. Twins Irish pub in New York City, NY.

Photograph by New York City artist Gerald Marks.

Armitage, H. (2020, April 6). 'Smart Toilet' monitors for signs of disease. Stanford Medicine News Center. https://med.stanford.edu/news/all-news/ 2020/04/smart-toilet-monitors-for-signs-of-disease.html

BBC News. (2020, April 24). Coronavirus: Twin sisters Katy and Emma Davis die with COVID-19. https://www.bbc.com/news/uk-england-hampshire52409765

Culliton, K. (2020, March 30). NYC doctor who separated conjoined twins dies of coronovirus. yahoo! news. https://news.yahoo.com/nyc-doctor-separatedconjoined-twins-174751067.html

Dhondalay, G. K. R., Bunning, B., Bauer, R. N., Barnathan, E. S., Maniscalco, C., Baribaud, F., ... Andorf, S. (2019). Transcriptomic and methylomic features in asthmatic and non-asthmatic twins. Allergy, 75, 989-991.

González-Valenzuela, M. J., López-Montiel, D., Cazorla-Granados, O., \& González-Mesa, E. (2020). Type of delivery and reading, writing, and arithmetic learning in twin births. Developmental Psychobiology, 62, 484-495.

Kaiser, E. (2020, April 1). Meet Covid and Corona - twins born during the lockdown in Chhattisgarh. The New Indian Express. https://www. newindianexpress.com/good-news/2020/apr/01/meet-covid-and-corona-— twins-born-during-the-lockdown-in-chhattisgarh-2124424.html

Kilgannon, C. (2020, May 15). She's 108, lived through the Spanish flu and just beat Covid-19. New York Times. https://www.nytimes.com/2020/05/15/ nyregion/sylvia-goldsholl-recovered-coronavirus.html

KIRO-7 TV. (2020). Dave Wagner. https://www.kiro7.com/author/dave-wagner/ Legacy. (2020). Patrick Lunney. https://www.legacy.com/obituaries/name/ patrick-lunney-obituary?pid $=192622900$

Marshall, M. (2020, April 18). COVID-19-A Blessing for Pangolins? The Guardian. https://www.theguardian.com/environment/2020/apr/18/ COVID-19-a-blessing-for-pangolins

Maynard, M. (2011, April 1). Twinco takes control. https://www. contractingbusiness.com/hvacrdb/article/20859317/twinco-takes-control

nature.com. (2020). Transcriptomics. https://www.nature.com/subjects/ transcriptomics

Park, S. M., Won, D. D., Lee, B. J., Escobedo, D., Esteva, A., Aalipour, A., . . Lozano, A. X. (2020). A mountable toilet system for personalized health monitoring via the analysis of excreta. Nature Biomedical Engineering. https://www.nature.com/articles/s41551-020-0534-9

Segal, N. L., \& Montoya, Y. M. (2018). Accidental brothers: The story of twins exchanged at birth and the power of nature and nurture. St. Martin's Press. 
Science + Insight. (2020). Methylation profile: Plasma. Doctors Data. https:// www.doctorsdata.com/methylation-profile-plasma/

Seelye, K. Q. (2020, April 24). Philip Kahn, 100, dies; Spanish flu took his twin a century ago. New York Times. https://www.nytimes.com/2020/04/ 24/nyregion/philip-kahn-dead-coronavirus.html?smid=fb-nytimes\&smtyp $=$ cur

Simon, M. (2020, March 31). New York neurosurgeon who separated conjoined twins dies from complications of COVID-19. CNN. https://www.cnn.com/ 2020/03/30/health/new-york-neurosurgeon-death-coronavirus-mcdonald-twins/ index.html

Top Documentary Films. (2020). Extraordinary people: The Rainman twins. https:/topdocumentaryfilms.com/extraordinary-people-rainman-twins/

Twins Irish Pub. (2020). Welcome to Twins Irish Pub. https://1970twinsirish pub.com/

World Wildlife Fund. (2020). What is a pangolin? https://www.worldwildlife. org/stories/what-is-a-pangolin 